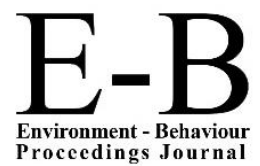

\title{
AicE-Bs2016Edinburgh
}

$7^{\text {th }}$ Asia-Pacific International Conference on Environment-Behaviour Studies, St Leonard Hall, Edinburgh University, United Kingdom, 27-30 July 2016

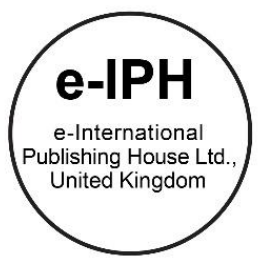

\section{Intention to Revisit and to Purchase: The effects of user's attitude in game advertising}

\author{
Zuhal Husseina ${ }^{\star}$, Nabsiah Abd Wahidb \\ a. Faculty of Business Management, Universiti Teknologi MARA (UiTM), Kota Bharu Campus, Wisma KUB, \\ Jalan Sultan Ibrahim, 15050, Kota Bharu Kelantan, Malaysia \\ b. Graduate School of Business, Universiti Sains Malaysia (USM), 11800 Pulau Pinang, Malaysia
}

\begin{abstract}
The aim of this study is to explore the effects of attitude on the user's intention to purchase and to revisit the game. This experimental study recruited 224 subjects on a voluntary basis through random sampling using a survey method. A questionnaire was used as an instrument to gather the data for this study. Data were analyzed using multiple regression analysis. The results found that attitude significantly affected the purchase intention of games advertised and significantly influenced users' intention to revisit the game.
\end{abstract}

(C) 2016. The Authors. Published for AMER ABRA by e-International Publishing House, Ltd., UK. This is an open access article under the CC BYNC-ND license (http://creativecommons.org/licenses/by-nc-nd/4.0/).

Peer-review under responsibility of AMER (Association of Malaysian Environment-Behaviour Researchers), ABRA (Association of Behavioural Researchers on Asians) and CE-Bs (Centre for Environment-Behaviour Studies), Faculty of Architecture, Planning \& Surveying, Universiti Teknologi MARA, Malaysia.

Keywords: Attitude; Game advertising; Purchase intention; Revisit the game

\section{Introduction}

Despite the current economic growth in Malaysia, it is important to note that the marketing industry worldwide is shifting to an age of content creativity to engage with consumers. As stated above, content creativity is driven by innovativeness and fantastic content that stand out from the advertising medium of others with the aim of capturing users' attitude, intention and behavior towards the in-game advertising content, for example via the product, brand, persuasive messages and interactive design. Thus, marketers need to think like content producers (i.e. content is a task by engaging consumers around their brand) rather than thinking like the traditional marketers (i.e. marketers act

\footnotetext{
* Corresponding author. Tel.: +012 2811774

E-mail address: zuhalhk@yahoo.com
}

2398-4287 @ 2016. The Authors. Published for AMER ABRA by e-International Publishing House, Ltd., UK. This is an open access article under the CC BY-NC-ND license (http://creativecommons.org/licenses/by-nc-nd/4.0/).

Peer-review under responsibility of AMER (Association of Malaysian Environment-Behaviour Researchers), ABRA (Association of Behavioural Researchers on Asians) and CE-Bs (Centre for Environment-Behaviour Studies), Faculty of Architecture, Planning \& Surveying, Universiti Teknologi MARA, Malaysia.

DOI: http://dx.doi.org/10.21834/e-bpj.v1i4.381 
only as disseminators of product information, while consumers need to learn about the brand themselves). This new school of thought is important to help marketers develop and build on the new idea of interactive advertising.

There is an increasing trend in the usage of interactive entertainment application especially gaming, attributed to easy Internet access and rapid advancement in Broadband facilities. The Pew Internet Project survey (marketingcharts.com) reported that some 53 percent of adults aged 18 and above play video games every day or almost every day. This finding sends a positive signal for marketers to grab this opportunity to integrate their products and brands in the virtual gaming environment exposed to those potential customers or users. If they can create a real game environment with an informative (product brand) advertisement, then a high traffic volume of users to visit and play the game may be assumed. This means that marketers should be targeting information technology savvy consumers, the game players or users and consider using interactive gaming as part of their marketing strategy for in-game advertising.

Although marketers are benefiting from the increased number of game players, it is imperative to investigate whether interactive advertising is so effective in reaching customers and affecting their behavior (Venkatesh, Davis, \& Morrison, 2007). Existing literature and research calls for further investigation of the potential use and effect of ingame advertising in computer games, in which most users were said to prefer real object placement inside the game to make it more natural (see, among others, Molesworth, 2003; Grigorovici \& Constantin, 2004). As Molesworth (2003, p.11) argues, brand realism can deliver persuasive messages within computer games to targeted user consumers. Similarly, Dickey (2005, p.78) suggests that game design takes into account game users' time and emotions as part of the in-game advertising approach. Therefore, this study will explore the user's attitude with regards to their purchase intention, as well as their intention to revisit in-game advertising.

\section{Literature Review}

\section{User's attitude in game advertising}

Positive attitudes should predispose approachable tendencies which can cause game users to focus their attention on purchasing the advertised brand or to revisit the game; whereas negative attitudes should predispose avoidance tendencies which can cause game users to pay less attention. Fishbein and Ajzen (1975) defined attitude-behavior as a disposition to respond with some degrees of favorableness or un-favorableness to a psychological object. They are expected to predict and explain human behavior. Using this definition, this study of the attitude model looks at the criteria of attitude to predict the behaviors of users or game players.

Studies have shown that attitudes formed via direct product experience are stronger, more persistent, more stable, and more confidently held compared to attitudes formed on the basis of advertising (see, for e.g. Fazio \& Zanna, 1981; Smith \& Swinyard, 1988, Glasman \& Albarracin, 2006). From the game players' perspective, it is expected that when playing games, users are exposed to the advertised messages which cause the users to demonstrate a psychological tendency. Consequently, each of these beliefs carries evaluative implications where attitudes are automatically formed. Game players can produce an evaluation in the advertisement messages by considering the existing and accessible beliefs.

\section{User's attitude towards purchase intention}

Purchase intention, according to Howard and Sheth (1971) and Mathieson (1991), is defined as the probability that a consumer plans to buy a certain brand or product during a certain period of time; and this task is thus simplified by storing relevant brand information to establish the purchase decision. Lantos (2015) emphasized that consumer's beliefs and attitudes derived from direct product experience will be stronger than indirect experience. Purchase intention in this study is conceptualized based on research done by Spears and Singh (2004) of an individual 
consumer's tendency to make an effort to purchase a brand. This explains that during the game play experience, purchase intentions are expected to occur as game players tend to take personal action towards the brand.

Computer games enable game players to experience the product directly, which leads to game players' enthusiasm. A study by Jeong (2007) shows that entertainment value is important in consumers' evaluation to purchase apparel from catalogues. Chen, Griffith, and Shen (2005) highlighted that interactive advertising can be used as an effective advertising tool to drive brand understanding and continuity of purchase intentions. Therefore, this study hypothesized that users' attitude will significantly affect the intention to purchase the brand advertised.

\section{User's attitude towards the intention to revisit}

Eagly and Chaiken (1993) stated that behavioral intention is motivated by one's conscious plan to perform a specific behavior. Within the scope of game players' perspectives, a game content developer needs to predict the actual behavior of users' intention to continue/replay the game. Research by Rafaeli (1988) pointed out users' presence in an interactive environment could lead to increased intention, although the process may not be direct. Furthermore, it is anticipated that when a sense of presence is heavily used to affect 'revisit behavior', the link between users' awareness of the presence and repeated behavior can be established.

Studies predicting behavior by Hussein and Wahid (2016) and Van Der Heijden (2003) examined attitudes and the intentional behavior to revisit. In an earlier study on the interactive web site, Hoffman and Novak (1996) stated that measures of repeat visits to the interactive site are crucial to evaluating the effectiveness of such sites. It is also imperative for the game developer to understand that user's behavioral intention, as a measurement reflected by attitude, can help companies enhance marketing sales strategies (Hussein and Wahid, 2016). Taylor and Todd (1995) and Gelderman (1998) studied perception-based approaches to identifying consistency with the intention to use the technology.

Hussein, Wahid, and Saad's (2009) study highlighted the importance of giving players a feeling of inclusion in the game environment. The study further suggested that in developing game content, it is vital for content developers to create appealing designs that can influence players to replay the game. The study revealed that users who had positively benefited from the first experience of game playing had a higher intention to revisit the game.

A survey conducted by Engage Technologies and Nvision estimated that 80 percent of Internet users failed to revisit the same site because of low interactivity (Campbell and Ma, 2015; Dholakia, Zhao, Dholakia, \& Fortin 2000). On the other hand, interactive site with a lack of clarity of purposes will create bad customers' experience, resulting in customers not revisiting the same site (Asim \& Hashim, 2005).

Therefore, it can be postulated that there is a significant relationship between a user's attitude and their intention to revisit the game in game advertising.

\section{Methodology}

This study used an experimental method by recruiting two hundred twenty-four volunteered game players. Experimental method was adopted to ensure the cause and effect relationship between persuasive advertising in game mediated environment and the game player intention to be clearly established. The survey used a questionnaire as a tool to collect the data. The game used in this study was a strategic game evaluative in nature which was selected from the main processes of site identification, and game player survey preferences identification. The game was chosen as a representation of the telepresence game. The games were played on a desktop computer and the testing setting was free and comfortable, without any competing stimuli.

Before running the experimental treatment, the respondents were given a clear instruction in order to ensure respondents to comply strictly with the experiments procedures. They were requested to answer the questionnaires, immediately once they have completed the game play. Respondents were asked to indicate their agreements or disagreements based on a five-point Likert scale. The questionnaire contains two main parts, the first relating to 
information about respondents' demographic characteristics. The second part was designed to measure respondents' knowledge and experience of the telepresence in computer games.

The experiment was conducted in the university's computer laboratory setting. Finally, data were analyzed using multiple regression analysis.

\section{Findings}

A total of 224 respondents returned usable responses. Results from Table 1 shows that one hundred forty nine were women while seventy five were men (66.5 percent compared to 33.5 percent respectively). A total of 135 respondents were Malay (60.3 percent), another 79 were Chinese (35.3 percent), eight were Indian ( 3.7 percent) and two were of other races ( 0.7 percent). Overall, one hundred ninety six respondents were in the age group 21-25 years (87.5 percent) compared to 24 respondents in the $19-20$ years age group (10.7 percent), and only four respondents ( 1.8 percent), were above 25 years old.

Table 1: Profile of Respondents

\begin{tabular}{llll}
\hline Demographic / Social Variables & Categories & Frequency & Percentage (\%) \\
& & & \\
\hline Gender & Male & 75 & 33.5 \\
& Female & 149 & 66.5 \\
\hline Ethnicity & Malay & 135 & 60.3 \\
& Chinese & 79 & 35.3 \\
& Indian & 8 & 3.6 \\
& Others & 2 & 0.7 \\
\hline Age (Years) & $19-20$ & 24 & 10.7 \\
& 21 - 25 & 196 & 87.5 \\
& Above 25 & 4 & 1.8 \\
\hline Weekly game playing behavior & Less than 1 Hour & 11 & 4.9 \\
& 1 - 8 Hours & 155 & 69.2 \\
& Above 8 Hours & 58 & 25.9 \\
\hline Preferred Game Mode & Single player mode & 156 & 69.6 \\
& Multiple player modes & 68 & 30.4 \\
\hline
\end{tabular}

Data revealed that in terms of time allocated to game playing, most of the respondents ( 69.2 percent) played 1 to 8 hours per week, and 25.9 percent played a game for more than 8 hours per week. However, a majority of the players (97.8 percent) played games for free, and only 2.2 percent played paid games. This could be due to budget constraints since all the respondents are full-time students, with only a handful earning from part-time jobs. Lastly, on game mode, 156 respondents (69.6 percent) preferred single player mode compared to 68 respondents (30.4 percent) who opted for multiplayer mode.

Table 2: Results on Multiple Regression Analysis of Attitude and Intention to Revisit the Game and Purchase Intention

\begin{tabular}{lll}
\hline Variables & Intention to Revisit the Game(Beta) & Intention to Purchase (Beta) \\
\hline Attitude & $.726^{* *}$ & $.517^{* *}$ \\
R2 & .527 & .267 \\
Adj. R2 & .525 & .264 \\
F-Change & $245.432^{\star *}$ & $80.866^{\star *}$ \\
\hline
\end{tabular}

Note: $\mathrm{N}=224$

Significant levels: ${ }^{* *} p<.01 ;{ }^{*} p<.05$; 
The results revealed that attitude $(\beta=.726, p<.00)$ significantly influenced users' intention to revisit the game. This explained 52.7 percent of the intention to revisit the game, where $F$ change $=245.432,(p<.00)$.

The regression results on the attitude of purchase intention, which is R2 showed 26.7 percent that cumulatively explained 26.7 percent in purchase intention of the brand advertised. The results also revealed that attitude $(\beta=$ $.517, p<.00)$ significantly affected purchase intention of the brand advertised. Thus, from the results, the hypothesis was supported.

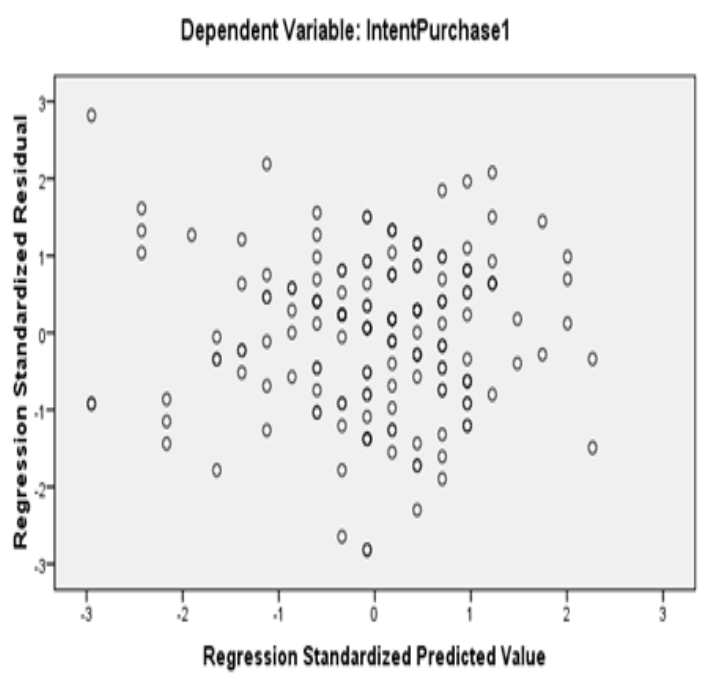

Figure 1: Scatterplot of Attitude towards Purchase Intention
Dependent Variable: IntentRevisit1

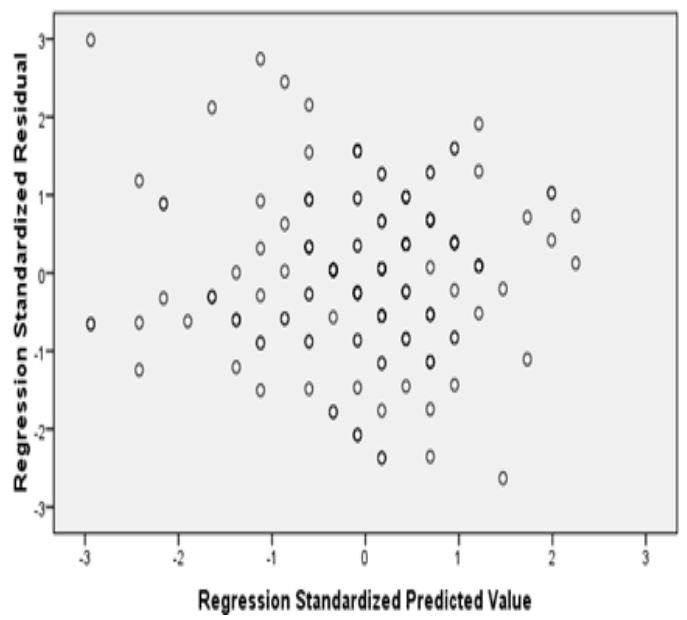

Figure 2: Scatterplot of Attitude towards Intention to Revisit

Both Fig. 1 and Fig. 2 show a random pattern indicating a good fit for a linear model. Both figures indicated a strong relation between predicted model and its actual results.

\section{Discussion and Conclusion}

This study found that attitude does influence the user's intention to revisit the game and significantly affected user's intention to purchase the brand advertised. These results were supported by previous studies done by Freygang \& Friorik (2013), Suh, Ahn \& Pedersen (2014) and Glasman\& Albarracin (2006). However, the effect is merely observed by the use of brand image per se, without further investigating users' experiences in high and low telepresence as well as single and multiple frequencies experiences, especially in the context of telepresence. Similar results were obtained for the influence of attitude on users' intentions to purchase the brand advertised, where respondents who mediated into the game environment tended to have a positive attitude, which subsequently influenced their intentions to purchase the advertised brand that appeared in the game environment positively. This result concurred with the finding of Glasman\& Albarracin (2006) study on consumer beliefs and attitudes when direct product experience is more clearly formed, more persistent, more confidently held, more accessible and more stable, this experience will lead to greater attitude-behavior consistency.

In conclusion, attractive advertising message in the game is also expected to be an effective communication tool with the capability of persuading the viewers to spend more time playing the games as well as engaging in favorable behavior through the development of a positive attitude. Another benefit is that understanding the game players' 
intention to revisit the game helps marketers save costs on retaining existing customers using the game as an advertising medium. Lastly, games require users' to provide their information before or while playing. The process is an easy way for marketers to gather useful information about the players to build up their own customer database. For future research, this study proposed for the researchers to investigate game player's attitude to revisit the game and to purchase the brand advertised in a different level of game exposure as it will give a better impact to actual understanding of revisiting and purchase behaviours.

\section{Limitations}

This study has several limitations. First, this study focused on the game players, and the results could not be generalized to customers of other entertainment industries such as the movie industry, television, radio broadcast and print media industry. Secondly, for the data collection method, this study primarily depended on self-reported responses. The behavioral intention and outcome of this measurement were based on self-administered questionnaires by individual game players. Their perceptions cannot be verified as they are the perceptions of individuals which are very subjective in nature and not representative of each other. Their perceptions may also be different from other game players. However, this approach is widely used in this field of study.

\section{REFERENCES}

Asim, M., \& Hashim, Y. (2005). E-Loyalty Companies secret weapon on the web. Lulea University of Technology.

Campbell, C. \& Ma, J.J. (2015). Looking forward, looking back: Drawing on the Past to Shape the Future of Marketing, Proceedings of the 2013 World Marketing Congress.

Chen, Q., Griffith, D. A., \& Shen, F. (2005). The Effects of Interactivity on Cross-Channel Communication Effectiveness. Journal of Interactive Advertising, 5(2), 30-44.

Dickey, M. D. (2005). Engaging By Design: How Engagement Strategies in Popular Computer and Video Games Can Inform Instructional Design. ETR\&D, 53(2), 67-83.

Eagly, A. H., Chaiken, S., \& (1993). The psychology of attitudes: Harcourt Brace Jovanovich College Publishers

Fazio, R. H., \& Zanna, M. P. (1981). Direct Experience and Attitude-Behavior Controversy (L. Berkowitz ed. Vol. Advances in Experimental Social Psychology). New York: Academic Press.

Fishbein, M., \& Ajzen, I. (1975). Belief, Attitude, Intention and Behavior: an Introduction to Theory and Research: Addison-Wesley Publishing Company

Freygang, A.E.\& Friorik, E. (2013). The effects of in-game advertising on players' explicit and implicit memory, attitudes and purchase intentions. http://skemman.is/en/item/view/1946/13569

Glasman, L.R.\& Albarracin, D. (2006). Forming attitude that predict future behavior: A Meta-Analysis of the Attitude-Behavior Relation. Psychology Bulletin. 132(5): 778-822.

Gelderman, M. (1998). The relation between user satisfaction, usage of information systems and performance. Information \& Management, 35, $11-\mathrm{M}$.

Grigorovici, D. M., \& Constantin, C. D. (2004). Experiencing Interactive Advertising beyond Rich Media: Impacts of Ad Type and Presence on Brand Effectiveness in 3D Gaming Immersive Virtual Environments. Journal of Interactive Advertising, 5(1), 30-53.

Hussein, Z., Wahid, N. A., \& Saad, N. (2009). Behavioral Study on Malaysia Game Player Experiences: How the Embedded Information Inside the Computer Game and Affect to the Player Behavior. Paper presented at the 9th Global Conference on Business \& Economics 2009 
Hussein, Z. \& Wahid, N.A. (2016). The Effects of Attitude towards Telepresence on User's Intention to Revisit the Game in Different Levels of Exposure. ARBUHUM 2016, Bandung.

Hoffman, D. L., \& Novak, T. P. (1996). Marketing in Hypermedia Computer-Mediated Environments: Conceptual Foundations The Journal of Marketing, 60(3), 50 - 68 .

Howard, J. A., \& Sheth, J. N. (1971). The Theory of Buyer Behavior by The Journal of Marketing, 35(1).

Jasper, C. R., \& Ouellette, S. J. (1994). Consumers' perception of risk and the purchase of apparel from catalogs. Journal of Direct Marketing, $8(2), 23-36$.

Jeong, So Won, "The effects of product presentation on consumer experiences, emotion, and website patronage intention towards an apparel website" (2007). Retrospective Theses and Dissertations. Paper 14888.

Lantos, G.P. (2015). Consumer Behaviour in Action: Real-Life Applications for Marketing Managers. Routledge.

Mathieson, K. (1991). Predicting User Intentions: Comparing the Technology Acceptance Model with the Theory of Planned Behavior. Information Systems Research, 2(3), 173.

Molesworth, M. (2003). Encounters with consumption during computer-mediated play: the development of digital games as marketing communication media Digital Games Research Association(Level Up Conference Proceedings Utrecht: University of Utrecht).

Rafaeli, S. (1988). Interactivity: From new media to communication. Sage Annual Review of Communication Research: Advancing Communication Science 16, 110-134.

Smith, R., \& Swinyard, W. (1988). Cognitive Response to Advertising \& Trial: Belief Strength. Belief Confidence and Product Curiosity. Journal of Advertising, 17, 3-14.

Spears, N., \& Singh, N. S. (2004). Measuring attitude toward the brand and purchase intention. Journal of Current Issues and Research in Advertising, 26(2), $54-65$.

Suh, Y.I., Ahn, T.S. \& Pedersen, P.M.(2014). Sports Website Interactivity Effects: An Analysis of the Relationships between Interactivity, Attitudes, and Intentions to Revisit. Journal of Applied Sports Management, 6(3), 47-70.

Taylor, S., \& Todd, P. (1995). An integrated model of waste management behavior: A test of household recycling and composting intentions. Environment and Behavior, 27, 603-630.

Van der Heijden, H. (2003). Factors Influencing the Usage of Websites: the case of a generic portal in the Netherlands. Information and Management 40, 541-549.

Venkatesh, V., Davis, F. D., \& Morri, M. G. (2007). Dead or live? The development, trajectory and future of technology adoption research. Information Technology Research Institute, ITRI-WP084-0207(3/30/07). 